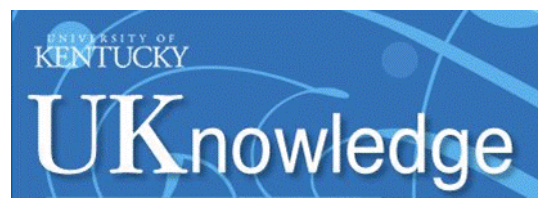

University of Kentucky

UKnowledge

\title{
Menstrual Disorders in the Adolescent Female
}

Donald E. Greydanus

Michigan State University

Shawn Sorrel

University of Kentucky

Hatim A. Omar

University of Kentucky, hatim.omar@uky.edu

Follow this and additional works at: https://uknowledge.uky.edu/pediatrics_facpub

Part of the Obstetrics and Gynecology Commons, and the Pediatrics Commons

Right click to open a feedback form in a new tab to let us know how this document benefits you.

\section{Repository Citation}

Greydanus, Donald E.; Sorrel, Shawn; and Omar, Hatim A., "Menstrual Disorders in the Adolescent Female" (2012). Pediatrics Faculty Publications. 101.

https://uknowledge.uky.edu/pediatrics_facpub/101

This Book Chapter is brought to you for free and open access by the Pediatrics at UKnowledge. It has been accepted for inclusion in Pediatrics Faculty Publications by an authorized administrator of UKnowledge. For more information, please contact UKnowledge@lsv.uky.edu. 


\section{Menstrual Disorders in the Adolescent Female}

\section{Notes/Citation Information}

Published in Adolescent Medicine: Pharmacotherapeutics in General, Mental and Sexual Health. Donald E. Greydanus, Dilip R. Patel, Hatim A. Omar, Cynthia Feucht, \& Joav Merrick, (Eds.). p. 301-330.

(C2012 Walter de Greyter GmbH \& Co. KG, Berlin, Boston

The copyright holder has granted permission for posting the chapter here.

Reprinted as an article in International Journal of Child and Adolescent Health, v. 5, no. 4, p. 357-378.

Reprinted as a book chapter in Child and Adolescent Health Yearbook 2012. Joav Merrick, (Ed.). p. 415-442. 


\section{Menstrual disorders in the adolescent female Donald E. Greydanus, Shawn Sorrel, and Hatim A. Omar}

This chapter reviews basic concepts of menstrual disorders in adolescents beginning with an overview of menstrual physiology followed by consideration of various abnormal menstrual patterns: amenorrhea (primary and secondary), dysfunctional uterine bleeding, dysmenorrhea (primary and secondary), and premenstrual syndrome.

\subsection{Introduction}

Menarche, or the onset of menstruation, occurs on average at 12.7 years of age in American females (approximately 12.16 years in African American females vs. 12.88 years in Caucasian females) (1). A responsive H-P-O (hypothalamic-pituitary-ovarian) axis induces cyclical menstruation that is regulated by levels of estrogen and progesterone and results in three classic menstrual phases: follicular, ovulatory, and luteal (2-4). Regulation of the onset and regularity of menses is under many influences, as listed in the following box (4). The level of exercise in adolescents involved in sports play can have considerable influence on their menstrual patterns (5).

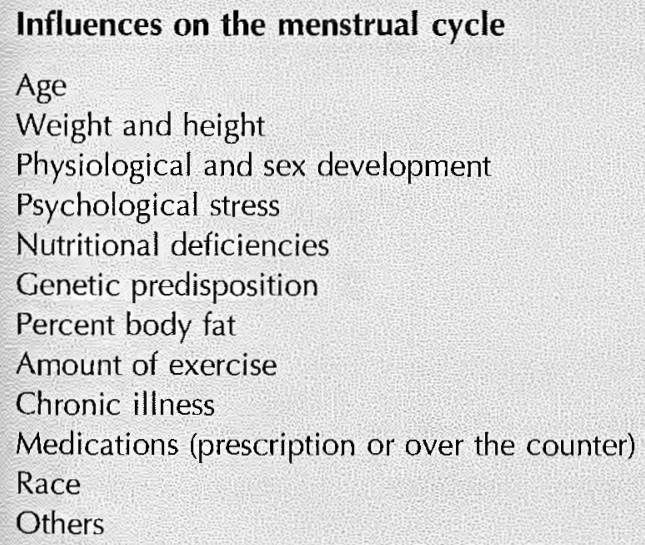

\subsubsection{Adolescent menstrual patterns}

The menstrual pattern of a mature female adult has a mean interval of 28 days ( \pm 7 days) and a median blood loss of $30 \mathrm{~mL}$ per month, with $60-80 \mathrm{cc}$ per month often set as upper limits of normal blood loss (6). There is more variability in the adolescent female, often due to lack of regular ovulation for several months to several years after menarche. Approximately half of her cycles are anovulatory in the first 2 years after 
menarche, and 20 percent are still without ovulation by the fifth menstrual year. The median cycle length for adolescent females is 31 days in the first 2 years after menarche, in contrast to 28 days for the adult female. Approximately 38 percent of cycles at 2 years after menarche are less than 40 days. This classic lack of ovulation in the adolescent female may result in oligomenorrhea, amenorrhea, or dysfunctional uterine bleeding (DUB). Definitions of menstrual abnormalities are noted in Tab. 17.1. Menstrual disorders discussed below include amenorrhea, DUB, and dysmenorrhea.

\subsection{Amenorrhea}

The absence of menses is called amenorrhea and is defined as primary or secondary amenorrhea $(7,8,9)$. The definition of primary amenorrhea is the absence of menstruation by 14 years of age with a sexually maturity rating (SMR) of 1 or by 16 years of age at a SMR of 2 or greater. Once menses has started, the lack of periods for three cycles or for 6 months defines secondary amenorrhea. Oligomenorrhea refers to infrequent, irregular menstrual bleeding over 45-day cycles. Although amenorrhea can be normal in the adolescent for 3 to 6 months for the first 2 years after menarche, a number of medical conditions can be the cause for an adolescent presenting with amenorrhea (primary or secondary) or oligomenorrhea (see Tabs. 17.2 and 17.3). Tabs. 17.2 and 17.4 and the box "Methods to Evaluate Hypoestrogenemia in Adolescents," list various laboratory tests useful in this clinical evaluation. The most common cause of secondary amenorrhea is pregnancy. Once pregnancy has been ruled out, laboratory testing will eliminate or confirm hyothyroidism and hyperprolactinemia as potential diagnoses. It is helpful to consider the remaining causes of secondary amenorrhea classified as normogonadotropic amenorrhea, hypogonadotropic hypogonadism, and hypergonadotropic

Tab. 17.1: Menstrual disorders definitions.

1. Normal adult menstrual cycle:

a. Mean interval of 28 days ( \pm 7 days)

b. Duration of menses of 4 days $( \pm 2-3$ days)

c. Median blood loss is about $30 \mathrm{~mL}$ per month (with the upper limit of normal defined as $60-$ $80 \mathrm{~mL}$ per month).

2. Amenorrhea: Absence of menses; can be primary or secondary (absence of three consequent menstrual cycles, after regular periods have been established)

3. Oligomenorrhea: Infrequent, irregular bleeding at $>45$-day intervals

4. Menorrhagia: Prolonged ( $>7$ days) or excessive $(>80 \mathrm{~mL}$ ) uterine bleeding occurring at regular intervals

5. Metrorrhagia: Uterine bleeding occurring at irregular but frequent intervals, the amount being variable

6. Menometrorrhagia: Prolonged uterine bleeding occurring at irregular intervals

7. Hypermenorrhea: Synonymous with menorrhagia

8. Polymenorrhea: Uterine bleeding occurring at regular intervals of $<21$ days

9. DUB: abnormal (different from that patient's normal) uterine bleeding that is unrelated to any anatomic lesion

Reprinted, with permission, from (1, p. 547). 
Tab. 17.2: Gynecologic disorders of adolescent females.

\begin{tabular}{|c|c|c|c|}
\hline Gynecologic Disorder & Special Comments & Differential Diagnosis & Laboratory Testing \\
\hline Amenorrhea (primary) & $\begin{array}{l}\text { Physiological is the main cause; Mayer- } \\
\text { Rokitansky-Kuster-Hauser (MRKH) } \\
\text { syndrome assoc. with renal abnormalities } \\
\text { and spinal malformations. Short stature } \\
\text { with delayed sexual maturation: Turner } \\
\text { syndrome; delayed sexual maturation + } \\
\text { hypertension seen in } 17-\alpha-\text { hydroxylase } \\
\text { deficiency; Swyer syndrome; absence of } \\
\text { smell sense suggests Kallmann syndrome; } \\
\text { visual field deficits suggest brain tumor. }\end{array}$ & $\begin{array}{l}\text { Physiological Imperforate hymen } \\
\text { MRKH syndrome; Turner syndrome } \\
\text { (45, XO and mosaicism) Chronic } \\
\text { Illness Hypothalamic: Stress, eating } \\
\text { disorders, exercise, depression; } \\
\text { Androgen insensitivity syndrome ( } 46 \\
\text { XY); Swyer syndrome; others: see } \\
\text { section } 17.2\end{array}$ & $\begin{array}{l}\text { Serum gonodotropins (follicle stimulating } \\
\text { hormone [FSH], luteinizing hormone } \\
\text { [LH]), prolactin, thyroid stimulating } \\
\text { hormone; Pelvic Ultrasound MRI, Head } \\
\text { CT/MRI Renal ultrasound/intravenous } \\
\text { pyelogram (IVP); karyotype laparoscopy }\end{array}$ \\
\hline $\begin{array}{l}\text { Amenorrhea } \\
\text { (secondary) }\end{array}$ & $\begin{array}{l}\text { Pregnancy is the main cause: history of } \\
\text { sexual activity - may present with a } \\
\text { midline "pelvic mass"; causes of } \\
\text { oligomenorrhea and secondary } \\
\text { amenorrhea are essentially the same. } \\
\text { Also important is history of dietary habits, } \\
\text { exercise, stress; acne and hirsutism } \\
\text { suggest elevated androgen levels; } \\
\text { Athlete Triad Syndrome: amenorrhea, } \\
\text { dysfunctional eating patterns, osteopenia- } \\
\text { porosis. }\end{array}$ & $\begin{array}{l}\text { Pregnancy; lactation; } \\
\text { Stress, eating disorders, } \\
\text { Chronic illness, } \\
\text { Exercise-induced, } \\
\text { prolactinoma (headaches, visual field } \\
\text { deficits, galactorrhea) } \\
\text { PCOS; } \\
\text { See section } 17.2 .3 \text {. }\end{array}$ & $\begin{array}{l}\text { Pregnancy } \\
\text { Test ( } \beta \text {-hCG) } \\
\text { Progesterone challenge } \\
\text { Serum estrogen, FSH, LH; } \\
\text { bone mineral densitometry; } \\
\text { Serum prolactin } \\
\text { Thyroid screen; } \\
\text { Head CT }\end{array}$ \\
\hline $\begin{array}{l}\text { Dysmenorrhea } \\
\text { (primary) } \\
\text { Dysmenorrhea } \\
\text { (secondary) }\end{array}$ & $\begin{array}{l}\text { Pelvic pain during normal ovulatory } \\
\text { menstruation; no underlying pelvic } \\
\text { pathology. May also see gastrointestinal } \\
\text { symptoms, headache, myalgia, sweating. } \\
\text { May be seen at menarche or } 3+\text { years } \\
\text { postmenarche. }\end{array}$ & $\begin{array}{l}\text { Physiological } \\
\text { Endometriosis } \\
\text { Pelvic Inflammatory Disease (PID) } \\
\text { Reproductive tract anomalies } \\
\text { Pelvic adhesions } \\
\text { Cervical stenosis }\end{array}$ & $\begin{array}{l}\text { Laparoscopy } \\
\text { STD screen } \\
\text { Pelvic Ultrasound; MRI }\end{array}$ \\
\hline
\end{tabular}


Tab. 17.2: Gynecologic disorders of adolescent females. (Continued)

\begin{tabular}{|c|c|c|c|}
\hline Gynecologic Disorder & Special Comments & Differential Diagnosis & Laboratory Testing \\
\hline & & $\begin{array}{l}\text { Ovarian masses } \\
\text { Pelvic congestion syndrome } \\
\text { Rule out Urinary Tract or } \\
\text { Gastrointestinal causes }\end{array}$ & \\
\hline DUB & $\begin{array}{l}\text { Menstrual calendar useful to get accurate } \\
\text { history of menstrual pattern; get sexual } \\
\text { activity history; } \\
\text { Establish presence/absence of ovulation: } \\
\text { basal body temperature charts, serum } \\
\text { progesterone, urinary LH and possibly } \\
\text { endometrial biopsy. } \\
\text { rule out an STD; virilization evaluation } \\
\text { necessary if hirsutism present. }\end{array}$ & $\begin{array}{l}\text { Anovulatory bleeding; } \\
\text { Pregnancy, ectopic pregnancy; } \\
\text { coagulation disorders (as von } \\
\text { Willebrand disease, others), anatomic } \\
\text { lesions, endometrial pathology; } \\
\text { cervicitis or cervical dysplasia; PID; } \\
\text { ovarian cysts; polycystic ovary } \\
\text { syndrome; severe stress, rapid or } \\
\text { severe weight gain or loss, drug abuse; } \\
\text { see text. }\end{array}$ & $\begin{array}{l}\text { CBC, platelets, beta-HCG, Pap smear, PT, } \\
\text { PTT, bleeding time, other coagulation } \\
\text { disorders screening; D- } 21 \text { progesterone; } \\
\text { thyroid screen; STD screen; ultrasound } \\
\text { (transvaginal; pelvic), MRI; hysteroscopy. }\end{array}$ \\
\hline Ectopic pregnancy & $\begin{array}{l}\text { Pain with history of secondary } \\
\text { amenorrhea, often with vaginal bleeding. }\end{array}$ & See DUB differential & $\beta$-hCG; pelvic ultrasound \\
\hline Endometriosis & $\begin{array}{l}\text { Presentation in adolescence not the same } \\
\text { as in aduits. May have acyclic pain, } \\
\text { abnormal uterine bleeding, Gl } \\
\text { symptomatology }\end{array}$ & See secondary dysmenorrheal & $\begin{array}{l}\text { Laparoscopy } \\
\text { Laparotomy }\end{array}$ \\
\hline Mittelschmertz & $\begin{array}{l}\text { Pain associated with ovulation in the } \\
\text { middle of a menstrual cycle. May last } 1-3 \\
\text { days and be mild to severe. }\end{array}$ & See secondary dysmenorrhea & Menstrual calendar \\
\hline Ovarian masses & $\begin{array}{l}\text { Presents with a lateral location; abnormal } \\
\text { menses }\end{array}$ & $\begin{array}{l}\text { Ovarian cysts } \\
\text { Ovarian tumors (benign, malignant) } \\
\text { Polycystic ovary syndrome } \\
\text { Ectopic Pregnancy } \\
\text { Tubo-ovarian mass }\end{array}$ & $\begin{array}{l}\text { Pregnancy test } \\
\text { Pelvic Ultrasound }\end{array}$ \\
\hline
\end{tabular}


Pelvic inflammatory

disease (PID)

PCOS;

hyperandrogenemia

syndrome
STD that can lead to uterine tenderness, adnexal tenderness, tenderness on cervical motion, muco-purulent vaginal or cervical discharge; can see fever ( $T>101 \mathrm{~F}, 38.3$

C); polymicrobial disorder of the upper genital tract often precipitated by Neisseria gonorrhoeaeChlamydia trachomatis,

others (Gardnerella vaginalisMycoplasma hominis Ureaplasma

urealyticumHaemophilus influenzae,

coliforms, cytomegalovirus,

peptostreptococcus, and other anaerobes).

Can involve various combinations of

endometritis, salpingitis, tubo-ovarian

abscess, and pelvic peritonitis.

Complications include infertility, chronic

pelvic pain, ectopic pregnancy.

Insulin resistance with hyperinsulinemia,

hyperandrogenemia, and chronic

anovulation; can see irregular menses

(secondary amenorrhea, oligomenorrhea

DUB), hirsutism, possible virilization,

variable obesity, acanthosis nigricans,

possible bilateral enlarged ovaries.
Ectopic pregnancy, appendicitis,

pyelonephritis, ovarian cyst, septic

abortion, others.

(2)
Other causes of hyperandrogenism;

HAIR-AN Syndrome; Congenital

adrenal hyperplasia (11ß-hydroxylase,

21-hydroxylase, 3ß-hydroxysteroid

dehydrogenase deficiency); Cushing's

disease, hyperprolactinemia; Ovarian

or adrenal tumor; Mixed gonadal

dysgenesis ( $45 \mathrm{X} / 46 \mathrm{XY}, 45 \mathrm{X} / 46 \mathrm{XX}$

$46 X Y)$; Gonadal dysgensis with

virilization; true hermaphroditism
Nonspecific:

White blood cells on saline prep; elevated

ESR; elevated CRP; lab evidence of

Neisseria gonorrhoeae or Chlamydia

trachomatis;

Specific Criteria

Positive biopsy: Endometrium showing

endometritis: Evidence of PID on

laparoscopy; ultrasound or MRI showing

that fallopian tubes are thick and filled

with fluid; may be free fluid in the pelvis

or a tubo-ovarian complex.

$\mathrm{LH}, \mathrm{FSH}, \mathrm{T}-4$, prolactin, testosterone (tota and free), insulin level; lipid profile;

17- $\alpha$-hydroxyprogesterone; 24 hour urine

for free cortisol; dexamethasone

suppression test; Pelvic ultrasound

(Continued) 
Tab. 17.2: Gynecologic disorders of adolescent females. (Continued)

\begin{tabular}{|c|c|c|c|}
\hline Gynecologic Disorder & Special Comments & Differential Diagnosis & Laboratory Testing \\
\hline $\begin{array}{l}\text { Premenstrual } \\
\text { syndrome (PMS) }\end{array}$ & $\begin{array}{l}\text { Variety of symptoms start before and end } \\
\text { with menses }\end{array}$ & $\begin{array}{l}\text { Premenstrual dysphoric disorder } \\
\text { (PMDD); depression; anxiety; others, } \\
\text { depending on the presenting } \\
\text { symptoms; see text. }\end{array}$ & $D S M-I V(2000)$ criteria for PMDD \\
\hline
\end{tabular}

Abbreviations: $\mathrm{CBC}$ : complete blood count; Pap: Papanicolaou smear; STD: sexually transmitted disease; MRI: magnetic resonance imaging; GI: gastrointestinal; ESR: erythrocyte sedimentation rate; F; Fahrenheit; $\mathrm{C}$ : Centigrade; HAIR-AN: hyperandrogenism, hirsutism, insulin resistance, acanthosis nigricans; DSM-IVDiagnostic and Statistical Manual, 4th edn (American Psychiatric Association); PT: prothrombin time; PTT: partial thromboplastin time. *Reprinted with permission from Greydanus DE, Feinberg AR, Patel DR, Homnick DN, eds. The pediatric diagnostic examination. New York: McGraw-Hill, 2008. 
Tab. 17.3: Clinical classification of amenorrhea in the adolescent.

1. Primary Amenorrhea with Pubertal (Sex) Delay

A. Gonadal malformation

1. Turner syndrome (gonadal dysgenesis)

2. Testicular feminization syndrome (androgen insensitivity syndrome)

B. Hypothalamic-pituitary dysfunction

1. Physiological delay (most common)

2. Functional disorders: hypothalamic-induced: such as weight loss, eating disorders, exercise, stress, others

3. Organic disorders: prolactinoma, chronic illness, others

II. Primary Amenorrhea without Pubertal (Sex) Delay

A. Pseudoamenorrhea

1. Imperforate hymen

2. Transverse vaginal septum

B. MRKH syndrome (agenesis of vagina, cervix, uterus)

C. PCOS (hyperandrogenemia syndromes)

D. Chronic illness (including thyroid disorders)

E. Others

1II. Secondary Amenorrhea

1. Pregnancy (most common)

2. Hypothalamic-induced: such as weight loss, eating disorders, exercise, stress

3. PCOS (hyperandrogenemia syndromes)

4. Thyroid disorders

5. Pituitary disorders (pituitary adenoma)

6. Hypoestrogenemia (ovarian dysfunction or ovarian hypofunction)

7. Chronic illness

8. Others

Modified and reprinted with permission from (12).

Tab. 17.4: Laboratory testing for amenorrhea in adolescents.

Pregnancy test

Hormonal investigation:

- LH \& FSH: Increased in ovarian failure/dysgenesis; normal or decreased in others

- Thyroid hormone levels

- Prolactin levels

- If virilization/hirsutism present: DHEAS, $\mathrm{LH} / \mathrm{FSH}$ ratio (nl:<2.5:1), testosterone (total and free)

- Level of estradiol \& progesterone and/or

- Vaginal smear to evaluate for epithelial cell estrogenization

Pelvic ultrasound to define anatomy (uterus hypoplasia)

Vaginoscopy

Bone age

Chromosome evaluation 
Tab. 17.4: Laboratory testing for amenorrhea in adolescents. (Continued)

Antiovarian antibodies

Head CT/MRI

Pelvic/abdominal MRI

Renal ultrasound/IVP

Laparoscopy

hypogonadism, each having specific etiology. The most common causes of normogonadotropic amennorhea are outflow obstruction and hyperandrogenic chronic anovulation. Polycystic ovarian syndrome (PCOS) is the most common cause of hyperandrogenic chronic anovulation. The high prevalence of secondary amenorrhea seen in adolescent athletes warrants further discussion.

\section{Methods to evaluate hypoestrogenemia in adolescents \\ Physical and sex development (delay of sex development) Body weight \\ Bone mineral densitometry \\ Serum estradiol level \\ Vaginal maturation index \\ Vaginal smear to evaluate for epithelial cell estrogenization}

\subsubsection{Amenorrhea in adolescent athletes}

Amenorrhea and oligomenorrhea are commonly encountered in the adolescent athlete population $(10,11)$. Menarche may be delayed in an adolescent athlete five months for each year of intense, prepubertal exercise. Furthermore, secondary amenorrhea is well-described in female athletes participating in cycling, gymnastics, and running sports. Menstrual dysfunction is noted in 12 percent of swimmers as well as cyclists, 44 percent of ballet dancers, 50 percent of female triathletes, 51 percent of endurance runners, and up to 20 percent of strenuously exercising females in general (12). Research suggests that up to 15 percent of all female athletes and two-thirds of elite female athletes have menstrual dysfunction.

As noted in the previous box "Influences on the Menstrual Cycle," there are many factors influencing menstruation in adolescent athletes. Tabs. 17.2 and 17.3 note the etiology of amenorrhea. The most common cause of amenorrhea in athletes involved with intense exercise is hypogonadotropic hypogonadism in which there is dysfunction of the GnRH production and LH pulsativity. Low body fat, although is a factor, is not the sole reason for menstrual dysfunction. The role of leptin in the complex menstrual process is not yet clear. Previous theories implying that menstruation cannot occur below a body fat percentage of 17 percent are not proved (12). Low body weight by itself does not cause amenorrhea and the weight of a female athlete with no menses can be the same or even more than one with a normal menstrual pattern. 
The intense exercise pattern induces such a major energy drain that the caloric intake of this athlete is not sufficient to maintain normal menstrual function. Meeting the energy needs of the athlete is the cornerstone to restoring normal menstrual function. This treatment is further discussed.

\subsubsection{Management of amenorrhea}

The management of an adolescent female with amenorrhea or oligomenorrhea is determined by the underlying cause(s) of the menstrual dysfunction. If intense exercise pattern is a central theme, the clinician can recommend a reduction in exercise by 10 percent or more. Typically in the female athlete triad (i.e. irregular menses as amenorrhea, disordered eating, and osteopenia - osteoporosis) (4), eating patterns may be abnormal as well, and she should be advised to improve her nutritional intake, including taking calcium and vitamin D supplementation. Consultation with a sports nutritionist can help the patient ensure she is meeting the nutritional and caloric needs specifically during involvement in sports. If menstrual dysfunction is part of a chronic hypoestrogenemia (see the previous box, "Methods to Evaluate Hypoestrogenemia in Adolescents"), she is at increased risk for reduced bone mineral density, osteopenia and eventually osteoporosis. Females with chronic lack of menstruation and low bone mineral density (BMD) may never acquire a normal $B M D$ even if the menstrual pattern eventually is normalized.

Female athletes with low BMD are increased risk for the development of stress fractures. Daily supplementation with calcium $(1,000-1,500 \mathrm{mg}$ per day), vitamin D (400-800 IU per day), vitamin B complex, and vitamin E (100-200 IU per day) is recommended for this athlete with menstrual dysfunction and/or eating dysfunction (10). Approximately 50 percent of bone mass is acquired during the adolescent years, and thus, if the female adolescent athlete has a low BMD, estrogen supplementation (conjugated estrogen or oral contraceptives) is suggested by many clinicians in an attempt to help her prevent bone loss.

The American Academy of Pediatrics has recommended that the amenorrheic adolescent athlete not be given hormonal medication if she is within three years of menarche; instead, she should be advised to lower her exercise pattern intensity and correct her nutritional intake (including adequate calcium intake) (13). Estrogen supplementation (typically the oral contraceptive) is recommended for the amenorrheic athlete if she is over 3 years from menarche and over age 16; hormonal management can used for those under age 16 years, if there is a history of a stress fracture.

However, problems in the management of these athletes often arise. For example, many committed athletes will not lower their intense exercise patterns nor alter their unhealthy dietary habits. Also, estrogen supplementation is controversial and not proven to enhance or protect BMD, with or without weight gain. It is not currently proven what the actual acute or chronic implications are of chronic amenorrhea and potential estrogen deficiency in the female adolescent athlete or in other females with these issues.

The use of conjugated estrogen or the oral contraceptive does not correct the underlying menstrual dysfunction and after the estrogen is stopped, the abnormal menstrual pattern often resumes. There are a number of potential side effects to oral contraceptives, including breast tenderness, breast congestion, nausea, emesis, weight gain, 
and others. Some studies suggest that oral contraceptives under 50 mcg estrogen may not be helpful in preventing osteoporosis (4). BMD is usually the most reduced in those who are thin and not active. Intense exercise involving weight bearing leads to high mechanical forces neutralizing the low BMD effect of a thin body type; bone accretion may be enhanced by weight-bearing exercise, allowing some amenorrheic athletes (i.e. tennis players, ice skaters, runners, gymnasts) to have normal or increased BMD.

\subsubsection{Management of PCOS}

PCOS is characterized by hyperandrogenism and chronic oligo-ovulation (14). The clinical presentation is heterogenous and often difficult to recognize in adolescents due to the coinciding signs and symptom of puberty including increased androgen production. Tab. 17.2 provides key features as well as a differential diagnosis, and suggested laboratory evaluation. Tab. 17.5 lists laboratory results which may be found in PCOS and support the diagnosis. Tab. 17.6 lists potential management options for adolescent females with PCOS. Treatment of PCOS is multifactorial and includes addressing obesity if present, decreasing androgen levels, and improving insulin resistance.

Oral contraceptive pills (OCPs) are the mainstay of treatment in PCOS. OCPs decrease I.H secretion and thus decrease ovarian androgen secretion, protect the endometrium from unopposed estrogen stimulation, and increase sex hormone binding

Tab. 17.5: Laboratory test results in PCOS patients.

Hyperinsulinemia (fasting levels of glucose/insulin ratio <4.5)

LH : Mild $\uparrow$

FSH: Low limits of normal

LH-FSH ratio: $>2.5: 1$

Estrodiol: Moderate $\uparrow$

17-hydroxyprogesterone: mild $\uparrow$

Androgen: mild to moderate $\uparrow$ in levels

- free and total testosterone

- early morning urinary 17-ketosteroids

- androstenedione

- DHEAS (can also be normal)

Sex hormone-binding globulin: $\downarrow$

Prolactin: Mild $\uparrow$

Abnormal lipid profile

- $\downarrow$ high-density lipoprotein

- $\uparrow$ cholesterol

- $\uparrow$ very-low density lipoprotein

- $\uparrow$ low-density lipoprotein

- $\uparrow$ triglycerides 
Tab. 17.6: Management options for PCOS patients.

\author{
Combined oral contraceptives (COCs) \\ Transdermal (patch) contraption \\ Transvaginal hormonal contraceptives (NuvaRing) \\ Progesterone \\ Spironolactone (androgen receptor antagonist) (hirsutism) \\ Flutamide (androgen receptor antagonist) (hirsutism) \\ Metformin \\ Management of obesity \\ Management of acne vulgaris \\ Hair removal (electrolysis and thermolysis) \\ Ovulation induction (usually only for adults) \\ - Clomiphene citrate
}

- GnRH agonistic analogs (leuprolide acetate or nafarelin)

Laser "drilling" of the ovary ( $\downarrow$ ovarian stromal steroids by reducing the stroma)

Management of potential comorbid endocrinopathies

globulin which then decreases free testosterone to improve hirsutism and acne. No specific ocp has shown to be more effective; however, Yasmin which contains both ethinyl estradiol and drosperinone decreases both ovarian and adrenal androgen secretion. Medroxyprogesterone (Provera - $10 \mathrm{mg}$ ) or micronized progesterone (Prometrium) can also be prescribed to induce withdrawal bleeding if this is taken orally for 12-14 days each month.

The treatment of hirsutism can include shaving, bleaching, depilatories and electrolysis. Pharmacological treatment includes eflornithine (Vaniqua) which is an approved topical cream that acts as a hair growth retardant. Androgen receptor antagonists (such as spironolactone [50 to $100 \mathrm{mg}$ twice a day]) or antiandrogens (such as flutamide or cyproterone acetate), although they are not approved for the treatment of hirsutism, are commonly used. Metformin (Glucophage) can be used to lower serum insulin levels along with reducing ovarian cytochrome $\mathrm{P} 450 \mathrm{c} 17 \mathrm{a}$ activity and improving hyperandrogenism found in obese PCOS adolescent females. Please refer to the endocrine chapter (chapter 2) for treatment of diabetes mellitus. Early intervention with androgen suppression therapy along with exercise and proper nutrition can improve the lives of these youth in their future adulthood periods of life. It is also important to address comorbid conditions including depression and other mental health concerns. Future complications of adolescents with PCOS include the potential of endometrial carcinoma, diabetes mellitus (type 2), infertility, cardiovascular disease, and hyperlipidemia.

\title{
17.2.4 DUB
}

Excessive, sustained, or unpatterned uterine bleeding not caused by anatomical lesions defines DUB. It is one of the most common menstrual concerns of adolescent females and noted in about 15 percent of all females seeking gynecologic consultation. DUB 
may lead to anemia (ranging from mild to severe), absence from school (or work), spontaneous muscle or joint bleeding, or postsurgical bleeding. Tabs. 17.2 and 17.7 provide a list of DUB etiologies that include anovulation, complications of pregnancy, anomalies of the reproductive tract, disorders of coagulation, trauma, endocrinopathies, other systemic disorders, trauma, infection (such as PID), and others (4). $\gg$ Tab. 17.2 provides suggested laboratory tests that may be obtained in the evaluation of DUB.

Tab. 17.7: Causes of abnormal vaginal bleeding.

Exclude rectal, urethral, and other perineal bleeding

Vaginal or uterine abnormalities

- Trauma (coitus, rape, abuse)

- Foreign body (IUD, tampon, etc.)

- Infection

Vaginitis (trichomonas, gonorrhea)

Cervicitis

Endometritis (tuberculosis)

PID

Sexually transmitted condylomata (HPV) of cervix or vagina

- Tumor

Botryoid sarcoma

Polyps (uterine, cervical)

Ovarian cyst or tumor (mature teratoma, endometrioma)

Leiomyomatosis

Clear cell carcinoma of cervix or vagina (DES)

Other ovarian malignancy and metastatic malignancy

- Endometriosis

- Congenital malformations of uterus

Complications of pregnancy

- Threatened or spontaneous abortion

- Ectopic pregnancy

- Molar pregnancy

- Induced abortion

Coagulopathy

- Generalized

- Thrombocytopenia (idiopathic thrombocytopenic purpura; leukemia; lymphoma; aplastic anemia, hypersplenism)

- Platelet dysfunction (von Willebrand's disease; Glanzmann's disease)

- Clotting disorders (hemophilia; other coagulation factor deficiencies)

- Uterine production of menstrual anticoagulants 
Tab. 17.7: Causes of abnormal vaginal bleeding. (Continued)

DUB

- Normal variation

Midcycle ovulatory bleeding

Early postmenarcheal anovulation

Early postmenarcheal estrogen irregularities

- Chronic anovulation

- Exogenous steroids

- Oral contraception

Midcycle breakthrough bleeding

- Relative luteal progesterone deficiency

- Progestogens (oral agents; Norplant; Depo-Provera)

- Continual estrogens

- Other drugs

Danazol

Spironolactone

Anticoagulants

Platelet inhibitors

Chemotherapy drugs

Natural hormones from plant extracts (5-Dehydroepiandrosterone [5-DHEA], Dong Quai, Yam Extract)

- Systemic diseases

Hyperthyroidism or hypothyroidism

Adrenal insufficiency

Cushing's syndrome

Diabetes mellitus

Chronic liver disease

Crohn's disease; ulcerative colitis

Chronic renal disease

Systemic lupus erythematosus

Ovarian failure

- Hyperprolactinemia

Androgen excess

Exogenous androgens, PCOS, congenital adrenal hyperplasias

Androgen-producing ovarian or adrenal tumor

Estrogen excess

Granulosa-theca cell tumor of the ovary

Other tumors 
Tab. 17.7: Causes of abnormal vaginal bleeding. (Continued)

\author{
Hypothalamic \\ Emotional stress \\ Physical stress, especially exercise \\ - Ovulatory \\ Short luteal phase \\ Prolonged luteal phase (Halban's disease) \\ Luteal progesterone insufficiency
}

Abbreviations: IUD = Intrauterine device; HPV = human papillomavirus; DES: diethylstilbestrol Reprinted, with permission, from (1, p. 547).

\title{
17.2.5 DUB management
}

Treatment of DUB consists of treating the symptoms associated as well as the cause. The first step, next to identifying the cause, is diagnosing the level of anemia, which is based on the classification of mild anemia (hematocrit over $33 \%$ or hemoglobin over $11 \mathrm{~g} / \mathrm{dl}$ ), moderate anemia (hematocrit $27 \%$ to $33 \%$ or hemoglobin 9 to $11 \mathrm{~g} / \mathrm{dl}$ ), or severe anemia (hematocrit under $27 \%$ or hemoglobin under $9 \mathrm{~g} / \mathrm{dl}$ and/or dropping) $(15,16)$.

\subsubsection{Absence of anemia or mild anemia}

Reassurance and monitoring over time is often all that is needed for mild DUB with no or mild anemia. The patient can be instructed to carefully follow her menstrual cycles with a menstrual calendar that can be presented at the office visits for review by her clinician. If mild anemia is present evaluate dietary inatke and supplement with $300 \mathrm{mg}$ of ferrous sulfate three times a day. The following box outlines potential adverse effects from iron supplementation. A slow release formulation can decrease some side effects. Constipation is a common side effect and therefore, a stool softener is often started when iron is supplemented. Vitamin $\mathrm{C}$ is often also added to each dose of ferrous sulfate to enhance absorption.

\section{Adverse effects of iron supplementation \\ Nausea \\ Emesis \\ Constipation (add stool softener to prevent) \\ Diarrhea \\ Stools that are black \\ Discoloration of urine \\ Worsening ulcers/colitis}


In addition to treating the anemia, COCs (also, patch or NuvaRing) can be used for to help regulate her menses and help avoid unwanted pregnancy. Depo-medroxyprogesterone acetate (DMPA) is not typically recommended as it may worsen the menstrual irregularity and potentially lead to amenorrhea; an intramuscular injection should be avoided in those with coagulation disorders. NSAIDs (nonsteroidal anti-inflammatory drugs) are helpful in reducing menstrual blood flow by as much as 50 percent via a direct effect on the endometrium that balances the vasodilator prostaglandin 12 and the potent vasoconstrictor thromboxane A2 (17-19).

\subsubsection{Moderate anemia}

The COC (typically a 30 to 35 mcg ethinyl estrodiol type) is used to control bleeding in patients with DUB marked by moderate anemia. The importance of estrogen is that it binds to receptors in the endometrium, provides stabilization of the endometrial vasculature and stroma, and stimulates specific growth factors. The pill can be provided in a dose of two to four times a day until the bleeding is stopped and then gradually tapered over 14 to 21 days to allow for withdrawal bleeding. It can be continued at a once a day dosage for the next few months or longer if necessary. A longer dosing pattern (3-6 months) will also allow correction of the underlying anemia. Higher levels of estrogen may cause nausea and therefore, an antiemetic medication can be added to alleviate any nausea or emesis that may occur. Iron supplementation can be provided as discussed previously.

An alternative to use of the oral contraceptive is prescription of oral equine estrogen (2.5 mg for 21-25 days each month) followed by medroxyprogestone acetate (10 $\mathrm{mg}$ a day) for the last 7 days of the menstrual cycle. The use of progesterone-only agents is preferred by some clinicians, as outlined in Tab. 17.8. Initially high doses may be needed to induce endometrial atrophy and then estrogen can be continued to be prescribed for a number of days to avoid breakthrough bleeding. Some physicians add an oral progesterone agent over the last 10 days of the menstrual cycle each month to avoid unopposed estrogen effects, allow endometrial stabilization and allow organized

Tab. 17.8: DUB control with progesterone-only agents.

A. Medroxy-progesterone acetate (MPA)

1. $10 \mathrm{mg}$ every 4 hours, then QID -4 days, TID -3 days, BID -14 days)

2. High dose may be necessary: 40-80 $\mathrm{mg}$ per day or $100 \mathrm{mg}$ Depo IM/day

B. Norethindrone acetate

1. $10 \mathrm{mg}$ every 4 hours, then every $6-8$ hours to 12 hours; taper as bleeding decreases

2. May stay on $5 \mathrm{mg}$ every 12 hours for months if necessary with $\uparrow$ if necessary (as teen with aplastic anemia and low platelet count)

3. $0.35 \mathrm{mg}$ OD - BID for breakthrough bleeding

C. Megestrol acetate ( $80 \mathrm{mg}$ BID may be needed)

QID, four times daily; TID, three times daily; BID, twice daily; OD, once daily. Modified with permission from (4, p. 60). 
endometrial sloughing. Concerns about using cyclic oral progestin therapy include . potential bloating, acne vulgaris, increased appetite-induced weight gain, and reduced contraceptive effect.

\section{Severe anemia}

Intravenous fluids and blood products may be necessary in this situation along with high dose estrogen, such as use of intravenous conjugated equine estrogens (25 $\mathrm{mg}$ initially and repeat dose every $4-6$ hours for up to 4 doses $)(4,17,18,19)$. The high dose estrogen induces rapid hemostasis because of increased production of fibrinogen, increased activity of Factors $V$ and IX, and increased aggregation of platelets. Use of such high dose estrogen may increase thromoembolism risks. An antiemetic, again, is added to control the potential nausea and emesis. A progesterone agent is added to induce controlled withdrawal bleeding from the endometrium. Some clincians prefer to use an oral contraceptive dosing pattern (see the following box) to avoid use of intravenous estrogen.

\section{Oral contraceptive schedule to control severe DUB}

1. Utilize a monophasic combination oral contraceptive with at least $35 \mathrm{mcg}$ ethinyl estradiol.

2. Four times a day (with an antiemetic) until the bleeding stops

3. Three times a day for 4 days

4. Twice a day for 2 to 3 weeks

5. Allow a controlled withdrawal bleed.

6. Start the oral contraceptive and oral iron supplements at once a day for 3 to 6 months.

Modified with permission from $(4$, p. 60$)$.

\subsubsection{Management of DUB due to coagulation disorders}

Control of DUB in adolescent females with coagulation disorders can be complex and consultation with experts in hematology is recommended (4). The cornerstone of bleeding control is appropriate factor replacement therapy with additional pharmacological agents that include intranasal DDAVP (1-deamino-8-D-arginine vasopressin) (Desmopressin acetate), antifibrinolytics (epsilonamino caproic acid [Amicar] or tranexamic acid (Cyklokapron), COCs, and/or levonorgestrel-releasing IUD (Mirena see Tab. 17.9). COCs raise Factor VIII activity (FVIII:AC) in hemophilia carriers. In patients with von Willebrand's disease, estrogen raises Factor VIII/vWF-ristocetin cofactor activity, and partially corrects prolonged bleeding time. If there is a history of deep vein thrombosis, and estrogen is used to control severe DUB, coumadin should be added as adjunctive therapy. 
Tab. 17.9: Effects and benefits of levonorgestrel IUD.

A. Contraceptive effects

- Prevents fertilization

- Interferes with ovum development

- Interferes with sperm movement and ability to penetrate ovum

- Inhibits sperm survival

- Helps prevent egg release

- Thickens cervical mucus

B. Benefits

- Effective contraception for 5 years

- Eventual reduction in menstrual flow

- OK for those with coagulation disorders

- Up to a $90 \%$ reduction in bleeding

- 20\%-50\% with no menses after one year

- Good for those with mental retardation/developmental disorders

- Frequent amenorrhea

- Decreased dysmenorrheal

- Decreased premenstrual syndrome

- Very low rates of infectious complications

Modified with permission from (4, p. 64).

\subsubsection{Other DUB management options}

There are other treatment options commonly used in adults, but less commonly in adolescents with severe and/or persistent DUB. These potential management strategies include danocrine, GnRH agonists, and surgical options, such as dilation and curettage, and hysterectomy. Danazol (Danocrine) is a synthetic hormonal agent prescribed to manage endometriosis, breast cysts, and severe DUB in adult females. Its benefits includes estrogen suppression and cessation of menstruation (4). GnRh agonists (i.e. buserelin, leuprolide [Lupron Depo], and nafarelin [Synarel]) stop menstruation, but there is limited research data on their use in adolescent females.

\subsection{Dysmenorrhea}

Dysmenorrhea is typically divided into primary and secondary dysmenorrhea. Primary dysmenorrhea refers to menstrual pain with no underlying pelvic pathology; secondary dysmenorrhea refers to pelvic (menstrual) pain resulting from anatomic and/or pelvic pathology. Tab. 17.2 outlines the definition and differential diagnosis for dysmenorrhea. Primary dysmenorrhea is often classified as mild, moderate, and severe. Mild dysmenorrhea does not interfere with normal daily activities and only minimal analgesic 
support is needed. With moderate dysmenorrhea, there is some reduction in activities and the use of analgesics is necessary. Severe dysmenorrhea implies that regular activities do not occur during the active phase of the symptoms and analgesics are usually not beneficial. Approximately two-thirds of ovulating females report some menstrual discomfort for 1 to 3 days of most ovulatory cycles with about half having mild dysmenorrhea, one-third with moderate cramping, and about 14 percent with severe dysmenorrhea (4).

Primary dysmenorrhea is the most common medical reason for school or work absence and it has an increasing incidence from the early adolescent years to young adulthood and first pregnancy $(20,21)$. Primary dysmenorrhea often starts 6 to 12 months postmenarche, though it may not been seen until the third year postmenarche. The pain associated with menstruation may start before the initiation of menstrual flow or once menstrual flow starts. The symptoms associated with dysmenorrhea can vary patient to patient and are illustrated in the box, "Features Associated with Primary Dysmenorrhea." When a patient presents with dysmenorrhea, the first step is to differentiate primary from secondary dysmenorrhea (see Tab. 17.2). It is also helpful to identify factors which can alleviate or aggravate the pain (see the box, "Factors That Improve or Worsen Primary Dysmenorrhea").

\section{Features associated with primary dysmenorrhea}

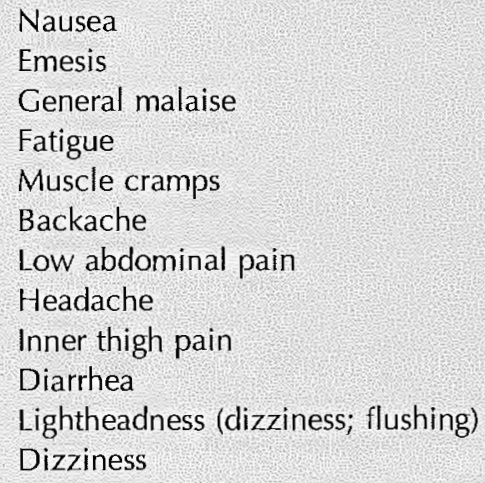

\section{Factors that improve or worsen primary dysmenorrhea}

Improve

- Parity

- Regular exercise

- Oral contraception

- NSAIDs

- Progesterone IUD 
Factors that improve or worsen primary dysmenorrhea (Continued)

Worsen

- Depression

- Anxiety

- Obesity

- Longer menstrual flow

- Copper IUD

\subsubsection{Etiology}

The etiology of the menstrual cramping in primary dysmenorrhea is due to the conditions set after ovulation occurs with the increase and decrease in progesterone levels that induce release of prostaglandins that stimulate a rise in uterine contractions and endometrial nerve endings' irritation (21-23). The result is variable menstrual cramping and pain due to a rise in myometrial resting tone, increased frequency and amplitude of contractions, and a rise in dysthythmic contractions. Those with primary dysmenorrhea have higher levels of circulating prostaglandins during menstruation in contrast to those without such cramping. In addition, research suggests that those with primary dysmenorrhea have heightened sensitivity to prostaglandins in the circulation and also higher vasopressin levels that can lead to increased uterine contractions and increased menstrual pain.

\subsubsection{Primary dysmenorrhea management}

\section{NSAIDs}

The initial pharmacological management for those with primary dysmenorrhea is NSAIDs that includes nonselective (COX-1 and COX-2 inhibitors) (see the following box) and selective or COX-2 inhibitors. Efficacy in the management of primary dysmenorrhea includes the suppression of cyclic endoperoxide synthetase at the cyclooxygenase level. In general, there is often no difference in efficacy and choice of therapeutic agents is determined by cost, convenience, adverse effects, and patient preference. It is thought that enolic acids (i.e. oxicams) not only may not be as effective for primary dysmenorrhea, but also has many more side effects.

\section{NSAIDs: Nonselective (COX-1 and COX-2 inhibitors)}

1. Salicylic acid esters: aspirin

2. Acetic acids: indomethacin, sulindac, tolmetin, nabumetone

3. Propionic acids: ibuprofen, naproxen, naproxen sodium, ketoprofen, flurbiprofen

4. Fenamic acids:mefenamic acid, meclofenamate

5. Enolic acids: piroxicam

Used with perimission from $(3$, p. 386). 
The NSAIDs with the highest benefit with lowest adverse effects are the propionic acids: ibuprofen, naproxen, naproxen sodium, and ketoprofen (see the previous box, "NSAIDs," and Tab. 17.10). Propionic acids are FDA approved for the treatment of primary dysmenorrhea and dosages are listed in $\$$ Tab. 17.10. Side effects include headache, gastrointestinal upset, heartburn, indigestion, rash, and dizziness. Naproxen sodium has a long half-life allowing for twice-a-day dosing. Ketoprofen has antibradykinin action, provides stabilization of lyosomal membranes, and inhibits prostaglandin as well as leukotriene synthesis.

Several propionic acids are available as over-the-counter agents and higher doses are available with prescription. As discussed previously, it is helpful for the patient to keep a calendar of her menstrual cycles so that she knows when her menses should start and can initiate pharmacological therapy. Medication can be continued for two to four days as needed for pain and reduction of blood loss. Partial to near complete pain improvement is noted in about 80 percent of those with primary dysmenorrhea. Failure of benefit may be due to absence of prostaglandin synthetase inhibitors blocking the 5-lipooxygenase pathway that allows continued production of leukotrienes. It is also important to remember that if there is no improvement in pain, secondary dysmenorrhea should be considered.

Salicylic acid esters (i.e. aspirin) is not efficacious in treatment of dysmenorrhea as it has limited anti-inflammatory effects on the endometrium. Indomethacin is an effective agent but has significant potential side effects including renal insufficiency, prolonged vaginal bleeding, headaches, gastrointestinal ulcers and gastric bleeding. Fenamic acids (mefenamic acid ( Tab. 17.10), meclofenamate) have a rapid onset of action and can reduce bleeding in patients with menorrhagia. These medications act by blocking myometrial receptor sites for synthesized prostaglandins as well as lead to inhibition of 5-lipooxygenase activity (with resultant leukotriene production suppression).

Tab. 17.10: NSAIDs for the treatment of primary dysmenorrhea.

\begin{tabular}{llll}
\hline Drug & $\begin{array}{l}\text { Initial Dose } \\
(\mathrm{mg})\end{array}$ & Maintenance Dose & $\begin{array}{l}\text { Maximum Dose/24 } \\
\text { hours (mg) }\end{array}$ \\
\hline Ibuprofen $^{\mathrm{a}}$ & 400 & $400 \mathrm{mg} \mathrm{q} \mathrm{4}$ hours & 3,200 \\
Ketoprofen $^{\text {Naproxen }}$ & $25-50$ & $25-50 \mathrm{mg} \mathrm{q} \mathrm{6-8} \mathrm{hours}$ & 300 \\
Sodium & 550 & $275 \mathrm{mg} \mathrm{q} \mathrm{6-8} \mathrm{hours} \mathrm{or} \mathrm{550} \mathrm{mg} \mathrm{q}$ & 1,375 \\
Naproxen & 500 & 12 hours & 1,250 \\
Mefenamic acid & 500 & $250 \mathrm{mg} \mathrm{q} \mathrm{6-8} \mathrm{hours} \mathrm{or} \mathrm{500} \mathrm{mg} \mathrm{q}$ & Not established \\
& & 12 hours & \\
\hline
\end{tabular}

${ }^{a}$ Available as over-the-counter drugs in the United States: ibuprofen, $200 \mathrm{mg}$ tablets; naproxen sodium, $220 \mathrm{mg}$ tablets.

*Used with perimission from (3, p. 387). 


\section{Oral contraceptives}

COCs may be used for primary dysmenorrhea if NSAIDS are not beneficial, as adjunctive management to NSAIDs, and also as first line therapy if the patient is seeking contraception. COCs prevent ovulation and this blocks the development of the postovulatory rise in prostaglandin levels because of the ovulation-induced corpus luteum. Blood flow is often reduced and menstrual cramps are lessened in up to 95 percent of females with primary dysmenorrhea on COCs. Other forms of hormonal contraception are also efficacious, such as the patch, transvaginal, injectable, or implantable (subdermal) methods. If a combination of NSAIDs and hormonal contraceptives are not helpful to a considerable extent, consider that the patient may have secondary versus primary dysmenorrhea (see Tab. 17.2). Other management options for treatment of primary dysmenorrhea are listed in the following box.

\section{Management options for primary dysmenorrhea}

NSAIDs (see the NSAIDs box and $>$ Tab. 17.10)

Hormonal contraception (pill, patch, transvaginal, injectable, implantable)

Use a menstrual calendar (to identify menstrual pattern)

Ensure adequate rest, sleep, and exercise

Reduction of psychological factors (as depression, anxiety, excess stress)

Fish consumption (omega- 6 fatty acids)

? Reduction of caffeine and sugar

Unproven methods

- Calcium channel blockers (i.e. nifedipine - tried in adult patients; can lead to headaches, hypotension)

- Acupuncture

- Transcutaneous electrical nerve stimulation

\subsubsection{Secondary dysmenorrhea}

There are many diagnoses in the differential for secondary dysmenorrhea including endometriosis, PID, reproductive tract anomalies (Mullerian defects), and others (see -Tab. 17.2). A careful medical history can often provide clues that an organic lesion is the cause of the dysmenorrhea. For example, the pain may begin at menarche or three years (or more) after the onset of menses. There may be atypical pain, pain associated with DUB or changing menstrual patterns, pain that is not relieved with NSAIDS and hormonal contraception, and pain that develops after pelvic surgery. The following box outlines questions to ask in the medical history to help delineate between primary and secondary dysmenorrhea. A careful examination and selective laboratory testing are necessary to identify the underlying cause ( Tab. 17.2). Management is dependent on the underlying etiology (4). Endometriosis is one of the most common causes of secondary dysmenorrhea. 


\section{Medical history in a patient with dysmenorrhea}

Age at menarche

Last time menstruation was regular (if at all)

Pain description: location, timing to menarche, menstrual flow, frequency

Severity of the pain: mild, moderate, severe (are activities disrupted?)

Do pain medications improve or relief the pain?

Flow description (duration and quantity)

Association with systemic factors

Sexual history and use of any contraception

History of pregnancy (and its outcome)

History of STDs

History of dyspareunia

History of other systemic disorders (i.e. gastrointestinal, genitorurinary, others)

History of surgical procedures

Family history of various gynecologic conditions (dysmenorrhea, endometriosis, ovarian cysts, infertility, virilization, cancer, others)

Used with perimission from $(3$, p. 384).

\subsection{Endometriosis}

The development of endometrial stroma and glands outside of the uterus defines the core feature of endometriosis. Though more commonly associated with adult females, it may been seen in half or more of adolescent females with chronic pelvic pain. Reflux of endometrial tissue from oviducts during menses may occur in a process termed retrograde menstruation; other mechanisms include the development of endometrial tissue from small cysts found over the pelvis, such as uterine surface, ovaries, pelvic ligaments, or the peritoneum (coelomic metaplasia). The precise underlying mechanisms are unclear, and thus various theories are proposed to explain why endometrial tissues are not cleared from nonuterine locations; these theories include immunologic deficiencies, lymphaticvascular metastases, and genetic factors. Recent research focuses on the major role of prostaglandin E2 (24). Pain arises in endometriosis because of swelling of endometrial cysts during menses, pelvic adhesion-induced pain, or stimulation of various pelvic nerve endings.

\subsubsection{Symptomatology}

Features consistent with endometriosis include severe dysmenorrhea unresponsive to analgesics or hormonal medication, chronic pelvic pain, and infertility. A variety of pain patterns exist depending on the location of the endometriotic lesions. There is 
no association between the number of lesions and the pain intensity. Abnormal menstrual bleeding can be seen along with various other symptoms, including clinical hematuria, suprapubic pain, dyspareunia, and/or dysuria. Variable gastrointestinal symptomatology may also be present and include pain with defecation (dyschezia), rectal pressure, and urgency. Endometriosis can also present with large ovarian endometriomas and adnexal masses.

\subsubsection{Diagnosis}

Identifying the pattern and location of pain can help in differentiating the etiology. - Tab. 17.11 outlines a diagnostic approach to adolescent females with pelvic pain. -Tab. 17.12 outlines a diagnostic plan for pelvic masses. A pelvic examination in a patient with endometriosis may be normal or reveal various abnormalities, such as pelvic tenderness, fixed (immobile) uterine, thickened broad ligaments, and/or unpredictable nodularity with or without tenderness. Various pelvic cysts or an adnexal mass may be noted by ultrasonography while a pelvic MRI may reveal genital reproductive tract anomalies. Females with endometriosis may have an increased CA-125 (cell surface antigen). Although this test has a low sensitivity and is not a cost-efficient screening test, levels of this antigen can be used to follow clinical response to treatment. The gold standard of diagnosing endometriosis is laparoscopy with biopsy and this should be performed in adolescent females with chronic pelvic pain of unknown cause not responding to NSAIDs and hormonal medication. Endometriotic lesions can appear differently in adolescent versus adult females (4).

Tab. 17.11: Differential diagnostic approach to pelvis pain.

\begin{tabular}{|c|c|c|}
\hline Characteristics of Pain & Likely Diagnosis & Confirmatory investigations \\
\hline \multicolumn{3}{|c|}{ Midline Location } \\
\hline \multirow[t]{2}{*}{ Cyclical, normal bleeding } & $\begin{array}{l}\text { Physiological } \\
\text { dysmenorrhea }\end{array}$ & History; pelvic examination (normal) \\
\hline & Endometriosis & $\begin{array}{l}\text { Pelvic examination; sonography; } \\
\text { laparoscopy }\end{array}$ \\
\hline \multirow[t]{2}{*}{ Acute, irregular bleeding } & Endometriosis & $\begin{array}{l}\text { Pelvic examination, cultures; } \mathrm{CBC} \text {; } \\
\text { sedimentation rate }\end{array}$ \\
\hline & $\begin{array}{l}\text { Threatened or septic } \\
\text { abortion }\end{array}$ & $\begin{array}{l}\text { History; pelvic examination; pregnancy } \\
\text { test }\end{array}$ \\
\hline \multirow{2}{*}{$\begin{array}{l}\text { Unrelated to menses, urinary } \\
\text { symptoms }^{a}\end{array}$} & Cystitis & History; urinalysis, urine culture \\
\hline & $\begin{array}{l}\text { Normal uterine } \\
\text { pregnancy }\end{array}$ & History; pregnancy test \\
\hline \multicolumn{3}{|c|}{ Lateral Location } \\
\hline Cyclical, normal bleeding & Mittelschmerz & $\begin{array}{l}\text { History (timing, nature); pelvic } \\
\text { examination (normal) }\end{array}$ \\
\hline
\end{tabular}


Tab. 17.11: Differential diagnostic approach to pelvis pain. (Continued)

\begin{tabular}{|c|c|c|}
\hline Characteristics of Pain & Likely Diagnosis & Confirmatory Investigations \\
\hline & Endometriosis & $\begin{array}{l}\text { Pelvic examination; sonography; } \\
\text { laparoscopy }\end{array}$ \\
\hline Acute, postmenstrual & Salpingitis or PID & $\begin{array}{l}\text { History; pelvic examination, cultures; } \\
\text { CBC, sed rate; laparoscopy }\end{array}$ \\
\hline Acute, abnormal bleeding & Ectopic pregnancy & $\begin{array}{l}\text { History; pelvic examination, pregnancy } \\
\text { test }\end{array}$ \\
\hline \multirow[t]{2}{*}{ Unrelated to menses, acute } & Appendicitis & $\begin{array}{l}\text { History; physical examination; CBC; } \\
\text { radiography }\end{array}$ \\
\hline & Ureteral colic & History; urinalysis; radiography \\
\hline \multirow{3}{*}{$\begin{array}{l}\text { Unrelated to menses, } \\
\text { chronic }\end{array}$} & Constipation & History; rectal examination \\
\hline & Pelvic osteomyelitis & $\begin{array}{l}\text { Physical examination; radiography; } \\
\text { gallium scan }\end{array}$ \\
\hline & Psychogenic & $\begin{array}{l}\text { History; exclusion of others; psychosocial } \\
\text { evaluation }\end{array}$ \\
\hline
\end{tabular}

Abbreviation: $\mathrm{CBC}=$ complete blood count.

aDysuria and urinary frequency may be associated with infection, pregnancy, and psychogenic factors.

Reprinted, with permission, from (1, p. 547).

Tab. 17.12: Differential diagnosis of pelvic masses.

\begin{tabular}{|c|c|c|}
\hline Characteristic of Mass & Differential Diagnosis & $\begin{array}{l}\text { Confirmatory History, Findings, } \\
\text { and Procedure }\end{array}$ \\
\hline \multicolumn{3}{|l|}{ Midline Location } \\
\hline & Pregnancy & $\begin{array}{l}\text { History of sexual activity; positive pelvic } \\
\text { examination }\end{array}$ \\
\hline \multirow[t]{2}{*}{$\begin{array}{l}\text { With amenorrhea or } \\
\text { abnormal menses }\end{array}$} & $\begin{array}{l}\text { Hematocolpos, } \\
\text { Hematometra }\end{array}$ & $\begin{array}{l}\text { History of no menses, cyclic pelvic pain; } \\
\text { perineal examination reveals imperforate } \\
\text { hymen, vaginal stenosis }\end{array}$ \\
\hline & Uterine sarcoma (rare) & $\begin{array}{l}\text { Negative pregnancy test; uterine } \\
\text { enlargement; sonography CT; tissue } \\
\text { diagnosis }\end{array}$ \\
\hline With normal menses & Bladder & $\begin{array}{l}\text { History of acute retention; findings of } \\
\text { herpetic or other lesions precipitating } \\
\text { retention; catheterization }\end{array}$ \\
\hline \multicolumn{3}{|l|}{ Lateral Location } \\
\hline $\begin{array}{l}\text { With amenorrhea or } \\
\text { abnormal menses }\end{array}$ & $\begin{array}{l}\text { Functioning ovarian cyst } \\
\text { (Tab. 17.2) Ovarian tumor }\end{array}$ & $\begin{array}{l}\text { History of menstrual irregularity; negative } \\
\text { pregnancy test; unilateral mass; physical or }\end{array}$ \\
\hline
\end{tabular}


Tab. 17.12: Differential diagnosis of pelvic masses. (Continued)

\begin{tabular}{|c|c|c|}
\hline Characteristic of Mass & Differential Diagnosis & $\begin{array}{l}\text { Confirmatory History, Findings, } \\
\text { and Procedure }\end{array}$ \\
\hline & & $\begin{array}{l}\text { laboratory evidence of hormonal } \\
\text { abnormalities; sonography, laparoscopy, } \\
\text { tissue diagnosis }\end{array}$ \\
\hline & PCOS (Tab. 17.2) & $\begin{array}{l}\text { As above with bilateral ovarian } \\
\text { enlargement }\end{array}$ \\
\hline \multirow[t]{5}{*}{ With normal menses } & $\begin{array}{l}\text { Ectopic pregnancy } \\
\text { (Tab. 17.2) }\end{array}$ & $\begin{array}{l}\text { History of sexual activity; pregnancy test } \\
\text { may or may not be positive; sonography; } \\
\text { may or may not have pain or tenderness; } \\
\text { may present as acute emergency }\end{array}$ \\
\hline & $\begin{array}{l}\text { Tuboovarian abscess } \\
\text { (Tab. 17.2) }\end{array}$ & $\begin{array}{l}\text { History and findings compatible with PID; } \\
\text { sonography, laparoscopy }\end{array}$ \\
\hline & $\begin{array}{l}\text { Nonfunctioning ovarian } \\
\text { cyst (Tab. 17.2) }\end{array}$ & $\begin{array}{l}\text { History of pain or asymptomatic; unilateral } \\
\text { mass; may be very large; sonography, } \\
\text { laparoscopy, tissue diagnosis }\end{array}$ \\
\hline & Appendiceal abscess & $\begin{array}{l}\text { History of appendicitis (or acute abnormal } \\
\text { condition); positive rectal or abdominal } \\
\text { examination; may be difficult to } \\
\text { distinguish from PID; sonography, } \\
\text { laparotomy }\end{array}$ \\
\hline & Fecal impaction & $\begin{array}{l}\text { History of constipation; positive rectal or } \\
\text { abdominal examination; abdominal } \\
\text { roentgenograms }\end{array}$ \\
\hline
\end{tabular}

Abbreviation: $\mathrm{CT}=$ computed tomography.

Reprinted, with permission, from (1, p. 559).

\subsubsection{Management of endometriosis}

Endometriosis is a complex and perplexing condition that should be managed in consultation with a gynecologist. There are many treatment options and these are listed in the following box. NSAIDs (Tab. 17.10) are usually not beneficial in females with endometriosis while hormonal medications may be useful in reducing (even removing) nonuterine endometriotic tissue. Clinicians can use oral contraceptives, patch contraception, transvaginal hormonal contraceptives, DMPA ( $150 \mathrm{mg}$ intramuscularly every 3 months), or oral MPA (30-50 mg once a day). Adverse effects of progestins include irregular bleeding, bloating, weight gain, and others. If COCs are contraindicated (see contraception chapter [chapter 19]), one may use a progestin-dominant oral contraceptive.

\section{Treatment options for endometriosis}

Oral contraceptives

Medroxyprogesterone acetate (Provera or Depo-Provera)

Androgens (methyltestosterone) 


\section{Treatment options for endometriosis (Continued)}

Gonadotropin-releasing hormone agonists (leuprolide acetate or nafarelin acetate)

Danazol (danocrine)

Anastrozole (Arimidex)

Laparoscopic ablation

Laser uterosacral nerve ablation

Electrocautery

Thermocoagulation

Laparotomy with resection of endometriomas

Presacral neurectomy

Correction of associated congenital reproductive anomalies

Modified with permission from $(4$, p. 104).

Danazol, a steroidal androgen can be used which suppresses cyclic changes and eventually causes atrophy of the endometriotic sites. Careful observation of potential adverse effects is important and these may include including fetal androgenisation, thrombotic events, elevated liver function tests, hyperlipidemia, acne vulgaris, weight gain, edema, and others.

Gonadotropin-releasing hormone agonists (leuprolide acetate or nafarelin acetate) can also be prescribed by themselves or in combined with estrogen. The addition of estrogen can help prevent the reversible state of menopause with amenorrhea, hot flashes, vaginal dryness, and loss of bone mass. If these agonists are used, they are usually stopped after 6 months unless estrogen is added to permit an additional 6 months use due to bone loss associated with GnRH agonist.

Aromatase inhibitors (anasazole) is used to treat postmenapausal breast cancer but can be used for adults with endometriosis; it may be combined with oral contraceptives or GnRh. This may be an option for women who have not had success with other treatment or unable to use other treatment modalities.

Surgical management is also useful for many with endometriosis as noted in the previous box, "Treatment Options for Endometriosis," and hormonal management can be continued after surgery to control the development of endometriosis that may occur after surgical treatment. Preservation of fertility is also the goal of any surgical procedure in the treatment of endometriosis.

\subsection{PMS}

PMS identifies various symptoms (see Tab. 17.13) that typically initiate during the latter luteal phase just before the onset of the menstrual flow and tend to resolve with the initiation of menstrual flow ( Tab. 17.2). Most reproductive females report PMS features and up to 8 percent note severe emotional symptoms (i.e. anxiety, depression, failure to perform daily activities) that meet the American Psychiatric Association's criteria for PMDD $(25,26)$. Various theories are proposed for PMS, though the precise causes are not known at this time (see the following box, "Proposed Theories for $\mathrm{PMS}^{\prime \prime}$ ). 
Tab. 17.13: PMS symptomatology.

Emotional Features

- Anecdotal reports of violence and suicide

- Anger

- Anxiety

- Concentration difficulties

- Crying

- Decreased libido

- Depression

- Feelings of being out of control or overwhelmed

- Lethargy

- Mood swings

- Withdrawal from usual activities

Physical Features

- Acne

- Anorexia

- Bloating

- Breast tenderness or swelling

- Constipation

- Diarrhea

- Edema

- Facial puffiness

- Fatigue

- Headache

- Increased appetite

- Lower abdominal or pelvic pain

- Pain: joints or muscles

- Swelling of hands

- Swelling of feet

- Weight gain

Used with permission from (3, pp. 388-89).

A careful evaluation is necessary to exclude PMS from such conditions as chronic fatigue syndrome, anemia, diabetes mellitus, hypothyrodism, collagen vascular disorders, and others. Adding to the confusion are the various conditions that may be worsened by menstruation; these include migraine headaches, erythema multiforme, acute intermittent porphyria, rheumatoid arthritis, recurrent anaphylaxis, and the three "periodic" conditions - periodic fever, paralysis, and hypersomnia. 


\section{Proposed theories for PMS}

Dysfunction of serotonin or $\gamma$-aminobutyric acid A (GABA-A)

I sensitivity to hydroxy-tryptamine $(5-H T)$ receptors

- (with $\downarrow$ with reduced levels and impaired uptake of serotonin)

Anxiety: dysfunctional interaction of metabolites of progesterone and receptors of

- $\gamma$-aminobutyric acid A (GABA-A) receptors

Panic Attacks: $\uparrow$ luteal phase levels of $\mathrm{P}_{\mathrm{CO} 2}$

Impact of recurrent episodes with $\uparrow$ sensitization and more PMS symptoms

Complex and perplexing interplay between various chemicals and systems:

- prostaglandins, endogenous opioid peptides, serotonin (other central

- nervous system neurotransmitters), ovarian steroids, and the peripheral

- autonomic nervous system

Miscellaneous psychological factors (contributory but not primary causative)

\subsubsection{Management of PMS}

Various supportive measures are typically recommended for PMS symptoms including regular exercise, healthy sleep-wake cycles, regular hot baths, reduced salt intake, reduced intake of caffeinated beverages (often high in adolescents), improved nutrition (with less sugar), abstinence from alcohol, and reduction in excessive stress. NSAIDs may improve breast or pelvic pain noted in some with PMS, while diuretics (such as spironolactone or hydrochlorothiazide) may relieve symptoms due to PMS weight gain or edema; abuse of diuretics, however, may lead to increased weight gain from increased edema.

Measures often suggested but without supportive research include herbal or vitamin supplementation. Such measures attempted, but without specific research to verify benefit, include oral contraceptives, progesterone, thyroid hormone supplementation, lithium, evening primrose oil, atenolol, prostaglandin inhibitors, vitamin E or B6 supplementation, and supplementation with calcium or magnesium.

Management of symptomatic anxiety or depression (or mental health disorders) is important. PMS emotional features (Tab. 17.12) may show some improvement with the judicious use of selective serotonin reuptake inhibitors (SSRIs), such as sertraline (50 $\mathrm{mg}$ daily), fluoxetine $(20 \mathrm{mg}$ daily), or paroxetine $(20 \mathrm{mg}$ daily). See the chapter on mood disorders (chapter 12) for review of the uses and potential side effects of SSRIs, including the FDA black box warning on increased suicidality in adolescence. Those with excessive symptoms of anxiety may benefit from prescription of anxiolytics such as alprazolam or buspirone. Some clinicians have used tricyclic antidepressants (such as clomipramine), though great care should be exercised in prescribing tricyclic antidepressants to adolescents due to the many side effects (27).

Measures used for adults with severe PMS include gonadotropin-releasing hormone $(\mathrm{GnRH})$ agonists (such as leuprolide [Lupron] and buserelin [Suprefact]). 
These agents produce a medical oophorectomy by suppression of gonadotropin release with resultant prevention of ovulation and ovarian hormone production. Adult females with severe mastalgia as part of their PMS have been prescribed bromocriptine, a dopamine-receptor agonist.

\subsection{Summary}

Menstrual disorders are common disorders in the adolescent female. This chapter reviews basic concepts of menstrual disorders in adolescents beginning with an overview of menstrual physiology followed by consideration of various abnormal menstrual patterns: amenorrhea (primary and secondary), DUB, dysmenorrhea (primary and secondary), and premenstrual syndrome.

\section{References}

1. Greydanus DE. Breast and gynecologic disorders. In: Hofmann AD, Greydanus DE, eds. Adolescent medicine, 3rd edn. Norwalk, CT: Appleton Lange, 1997:520-34.

2. Greydanus DE, Tsistika AK, Gains MJ. The gynecology system and the adolescent. In: Greydanus DE, Feinberg AN, Patel DR, Homnick DN, eds. The pediatric diagnostic examination. New York: McGraw-Hill, 2008:701-18.

3. Greydanus DE, Omar HA, Tsitsika AK, Patel DR. Menstrual disorders in adolescent females. In: Omar HA, Greydanus DE, Tsitsika A, Patel DR, Merrick J, eds. Pediatric and adolescent sexuality and gynecology. Principles for the primary care clinician. New York: Nova Science, 2010:317-411.

4. Greydanus DE, Omar HA, Tsitsika AK, Patel DR. Menstrual disorders in adolescent females. Curr Concepts Dis-A-Month 2009;55(2):39-114.

5. Greydanus DE, Tsitsika A. Special considerations for the female athlete. In: Patel DR, Greydanus DE, Baker R, eds. Pediatric practice: Sports medicine. New York: McGraw-Hill, 2009:86-101.

6. Greydanus DE, Patel DR. Medical aspects of the female athlete at puberty. Int Sports Med J 2004;5(1):1-25.

7. Greenfield TP, Blythe MJ. Menstrual disorders in adolescents. In: Greydanus DE, Patel DR, Pratt HD, eds. Essential adolescent medicine. New York: McGraw-Hill, 2006: 591-612.

8. Harber VJ. Menstrual cycle changes in athletic women: A review. Int Sports Med J 2004;5:56-66.

9. Deitch HR, Hillard PJ. Menstrual disorders in the college age female. Pediatr Clin North Am 2005:52:101-25.

10. Manore MM. Nutritional recommendations and athletic menstrual dysfunction. Int Sports Med J 2004;5:45-55.

11. Dusek T. High intensity training and menstrual cycle disorders in athletes. Int Sports Med J 2004;5:37-44.

12. Greydanus DE, Patel DR. The female athlete: before and beyond puberty. Pediatr Clin North Am 2002;49:553-80.

13. American Academy of Pediatrics. Medical concerns in the female athlete. Pediatrics 2000;106:610-3.

14. Guzick DS. Polycystic ovary syndrome Obstet Gynecol 2004;103:181-91. 
15. Kulkarni R, Gera R, Scott-Emuakpor AB. Adolescent hematology. In: Greydanus DE, , Patel DR, Pratt HD, eds. Essential adolescent medicine. New York: McGraw-Hill, 2006:111-45.

16. Friberg B, Orno AK, Lindgren A, Lethagen S. Bleeding disorders among young women: A population-based prevalence study. Acta Obstet Gynecol Scand 2006;85(2):200-6.

17. Matytsina LA, Zoloto EV, Sinenko LV, Greydanus DE. Dysfunctional uterine bleeding in adolescents: Concepts of pathophysiology and management. Prim Care Clin Office Pract 2006;33(2):503-15.

18. Strickland JL, Wall JW. Abnormal uterine bleeding in adolescents. Obstet Gynecol Clin North Am 2003;30(2):321-35.

19. Claessens EA, Cowell CA. Acute adolescent menorrhagia. Am J Obstet Gynecol 1981;139:277-82.

20. Ortiz MI, Rangel-Flores E, Carillo-Alarcón LC, Veras-Godoy HA. Prevalence and impact of primary dysmenorrhea among Mexican high school students. Int J Gynaecol Obstet 2009;107(3):240-3.

21. Ortiz MI. Primary dysmenorrheal among Mexican university students: Prevalence, impact, and treatment. Eur J Obstet Gynecol Reprod Biol 2010;152(1):73-7.

22. Dawood MY. Dysmenorrhoea and prostaglandins: pharmacological and therapeutic considerations. Drugs 1981;22(1):42-56.

23. Dawood MY. Primary dysmenorrheal: Advances in pathogenesis and management. Obstet Gynecol 2006;108(2):428-41.

24. Wu MH, Lu CW, Chuang PC, Tsai SJ. Prostaglandin D2: The master of endomietriosis? Exp Biol Med 2010;235(6):668-77.

25. American Psychiatric Association. DSM-IV: Diagnostic and statistical manual of mental disorders, 4th edn. Washington, DC: American Psychiatric Association, 1994.

26. American Psychiatric Association. DSM-IV-TR: Diagnostic and statistical manual of mental disorders, 4th edn, text rev. Washington, DC: American Psychiatric Association, 2000

27. Greydanus DE, Calles J, Patel DR. Pediatric and adolescent psychopharmacology: A practical manual for pediatricians. Cambridge: Cambridge University Press, 2008. 